\title{
The Tree Shrew as a Model for Cancer Research
}

\author{
Tao $\mathrm{Lu}^{1+}$, Hongmei Peng ${ }^{2 \dagger}$, Liping Zhong ${ }^{1}$, Pan Wu ${ }^{1}$, Jian $\mathrm{He}^{1}$, Zhiming Deng ${ }^{3 *}$ and \\ Yong Huang ${ }^{1 *}$ \\ ${ }^{1}$ National Center for International Research of Bio-targeting Theranostics, Guangxi Key Laboratory of Bio-targeting \\ Theranostics, Collaborative Innovation Center for Targeting Tumor Diagnosis and Therapy, Guangxi Talent Highland of \\ Bio-targeting Theranostics, Guangxi Medical University, Nanning, China, ${ }^{2}$ Scientific Research and Education Department, \\ The First People's Hospital of Changde City, Changde, China, ${ }^{3}$ The First People's Hospital of Changde City, Changde, China
}

OPEN ACCESS

Edited by:

Davide Zella

University of Maryland, Baltimore,

United States

Reviewed by:

Lin Zhang,

Hubei University of Chinese

Medicine, China

Yong Wu,

Wuhan Mental Health Center, China

Zhu Wanlong,

Yunnan Normal University, China

*Correspondence:

Yong Huang

huangyong503@126.com

Zhiming Deng

cdzm_deng@yeah.net

tThese authors have contributed equally to this work and share first authorship

Specialty section

This article was submitted to Molecular and Cellular Oncology,

a section of the journal

Frontiers in Oncology

Received: 14 January 2021

Accepted: 17 February 2021

Published: 09 March 2021

Citation:

Lu T, Peng $\mathrm{H}$, Zhong L, Wu P, He J,

Deng $Z$ and Huang $Y$ (2021) The Tree

Shrew as a Model for Cancer

Research. Front. Oncol. 11:653236.

doi: 10.3389/fonc.2021.653236
Animal disease models are necessary in medical research, and an appropriate animal model is of great importance for studies about the prevention or treatment of cancer. The most important thing in the selection of animal models is to consider the similarity between animals and humans. The tree shrew (Tupaia belangeri) is a squirrel-like mammal which placed in the order Scandentia. Whole-genome sequencing has revealed that tree shrews are extremely similar to primate and humans than to rodents, with many highly conserved genes, which makes the data from studies that use tree shrews as models more convincing and the research outcomes more easily translatable. In tumor research, tree shrews are often used as animal models for hepatic and mammary cancers. As research has progressed, other types of tree shrew tumor models have been developed and exhibit clinical manifestations similar to those of humans. Combining the advantages of both rodents and primates, the tree shrew is expected to be the most powerful animal model for studying tumors.

Keywords: animal model, cancer, immunity, primate, tree shrew (Tupaia belangeri)

\section{INTRODUCTION}

Cancer is the first or second leading cause of premature death globally and accounted for 4.5 million (29.8\%) of the 15.2 million premature deaths from non-communicable diseases worldwide in 2016 (1). Cancer treatments include surgery, chemotherapy, radiotherapy, targeted therapy, etc. However, patients with advanced cancer often have multiple metastases, and surgery can no longer cure these patients. The complex tumor microenvironment increases the difficulty of cancer treatment. There is an urgent need to develop effective targeted therapies or immunotherapies for patients with advanced cancer. Mammalian models are of great importance in the investigation of the underlying mechanisms of cancer and in the development of treatments and interventions. Typically, the animals used as models need to be similar to humans in terms of anatomy, physiology, immunology and pathology and have the advantages of being easy to handle and inexpensive and requiring a short experimental cycle time. For example, mice are the most common mammalian model, and mice have the advantages of being inexpensive and easy to handle and requiring short experimental cycles; however, the immune system of mice is somewhat different from that of humans and is not suitable for all tumor studies (2). 
A large number of animal models, such as Drosophila (3), mice (4), rabbits (5), dogs (6), pigs (7), rats (8), and rhesus macaque (9), are used in research to advance medicine. Each animal model has its strengths and weaknesses, and to date, no animal model has been created that can perfectly replicate human disease (10). For example, mice are widely used because of their clear genetic background, small size, and ease of handling. However, the genetic differences between mice and humans are substantial, making the clinical translation of many experimental achievements difficult. Large primates, such as orangutans, are very similar to humans in all respects and can very accurately simulate the physiopathological characteristics of human diseases. However, large primates are difficult to use as animal models due to high costs, operational difficulties, long experimental cycles and ethical restrictions (11). The tree shrew belongs to the family Tupaiidae, which is currently located in the order Scandentia. The genetic relationship between tree shrews and primates has been debated for a long time. The Kunming Institute of Zoology has recently reconstructed the phylogenetic relationships of tree shrews with 14 mammals (including six primate species) based on 2,117 single-copy genes in the whole genome of tree shrews, showing that tree shrews are more closely related to primates and resolving a longstanding controversy about the evolutionary status of tree shrews $(12,13)$. There are some common genetic properties between the tree shrew and human, such as genes/pathways involved in neuropsychiatric disorders and infectious diseases, common candidate drug targets squences, proteomic characterization of tree shrew liver and muscle tissues (14). There are also some unique genetic differences between the tree shrew and human. For example, the tree shrew lacked the OPN1MW [opsin 1 (cone pigments), medium-wave-sensitive] and OPN1NW2 [(opsin 1 (cone pigments), medium-wave-sensitive 2] among the visually related human genes. The antiviral gene RIG-I (retinoic acid inducible gene I) was also lost during evolution (14). As a close relative of non-human primates, the whole genome of the tree shrew has been sequenced, and the results show that the nervous, immune and metabolic systems of the tree shrew are similar to those of humans (15-17). The relevant genomic data can be queried in the tree shrew database (TreeshrewDB) (http:// www.treeshrewdb.org) (18). The tree shrew not only has the advantages of rodent models with small size, easy reproduction and short experimental periods but also has the advantage of high homology with primate models and humans. The data obtained from research using the tree shrew model are clinically instructive, and the tree shrew is well-suited for use as an animal model of human disease.

Tree shrews have been used in various disease models, such as infectious disease models (19), tumor models (20), metabolic disease models (21), and psychiatric and neurological disease models $(22,23)$. The development of inbred and transgenic tree shrews in recent years has further driven their widespread application $(24,25)$. Advanced tumors are complex and closely associated with immune, metabolic, and pathological phenotypes as well as genetic alterations. It is difficult for rodents to manifest disease characteristics that are similar in all respects to those of humans. The tree shrew has close homology with humans and exhibits pathological, physiological characteristics and immune responses similar to those of humans in tumor models, making tree shews become an appropriate animal model. However, the use of tree shrews for tumor modeling is still in the early stages, and some disadvantages remain, such as complex model construction methods and few tumor types; therefore, tree shrews are not widely used. In order to improve the efficiency of clinical translation of oncology research, it is imperative to promote the tree shrew tumor models. This paper reviews the anatomical features, physiological and biochemical characteristics, immune system and pathological tumor phenotypes of tree shrews, with emphasis on the various tree shrew tumor models constructed in recent years and their pathological phenotypes. Figure 1 shows tree shrew tumor models that have been successfully Induced in recent years.

\section{THE TREE SHREW ANATOMY}

Compared to rodents, tree shrews, as an animal model, can effectively bridge the gap between basic research and translational medicine. The anatomy of the tree shrew is both similar to and different from that of other primates. The presence, abundance and distribution of neural stem and progenitor cells in tree shrews are more similar to those of primates than to those of rodents. The tree shrew is a novel model organism for studying human brain disease (31). Micro-computed tomography and microdissection show that the cochlear structure and cochlear rotations of the tree shrew are highly similar to those of humans, and thus, tree shrews can be used for research on ear diseases (32). The lungs of the tree shrew have three left lobes and four right lobes, whereas the lungs of humans have only two left lobes and three right lobes. The livers of both tree shrews and humans have left, middle, right and caudate lobes, and the difference is that in tree shrews, the gallbladder is in the central lobe, whereas in humans, it is located below the right lobe of the liver (33). Compared to humans, the tree shrew has a relatively simple intestinal structure but a small primitive caecum (34). In addition, the morphology and histology of tree shrew skin is very similar to those of human skin. The dermis and subcutaneous tissues contain hair follicles, sebaceous glands, sweat glands and acinar glands, where keratin 5 (KRT5) and keratin 10 (KRT10) are expressed in the cytoplasm of the skin. Thus, tree shrews are also suitable for elucidating the molecular mechanisms of various skin diseases (35).

\section{TREE SHREW PHYSIOLOGY AND BIOCHEMISTRY}

Animal experiments are performed on the basis of characteristics that animals share with humans to some degree. In terms of physiology, it has been shown that the morphological characteristics of tree shrew blood cells are broadly similar to those of normal human blood cells. The red blood cell count $\left(8.19 \times 10^{12} / \mathrm{L}\right)$, red blood cell pressure volume $(70.75 \%)$ and platelet count $\left(450.17 \times 10^{12} / \mathrm{L}\right)$ are all slightly higher than the normative reference values, probably due to the tree shrew's own highly active behavior. The values for leukocytes $(2.21 \times$ $\left.10^{9} / \mathrm{L}\right)$ and neutrophils $\left(0.85 \times 10^{9} / \mathrm{L}\right)$ are below the lower limit 
A

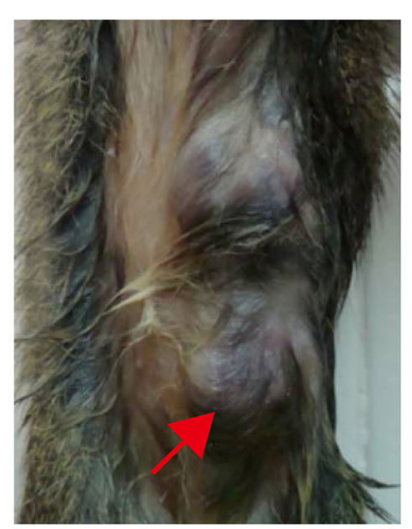

B

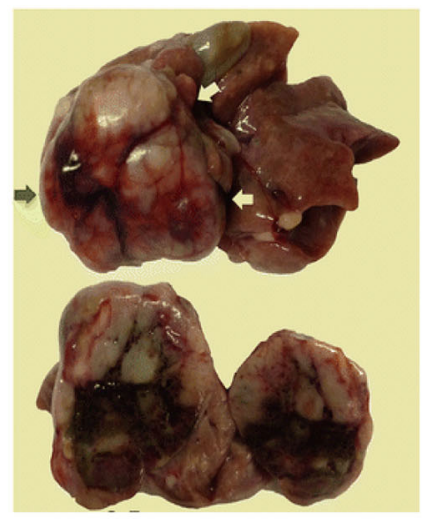

C

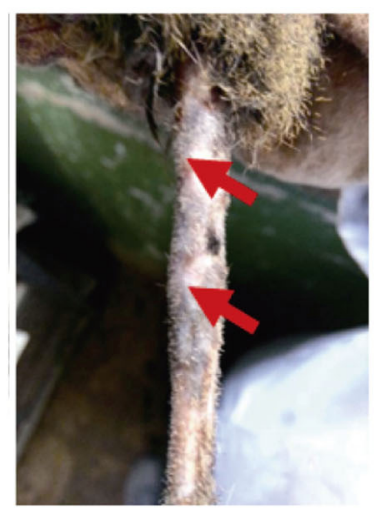

D

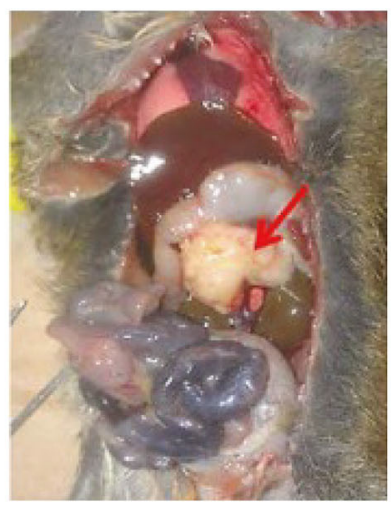

E

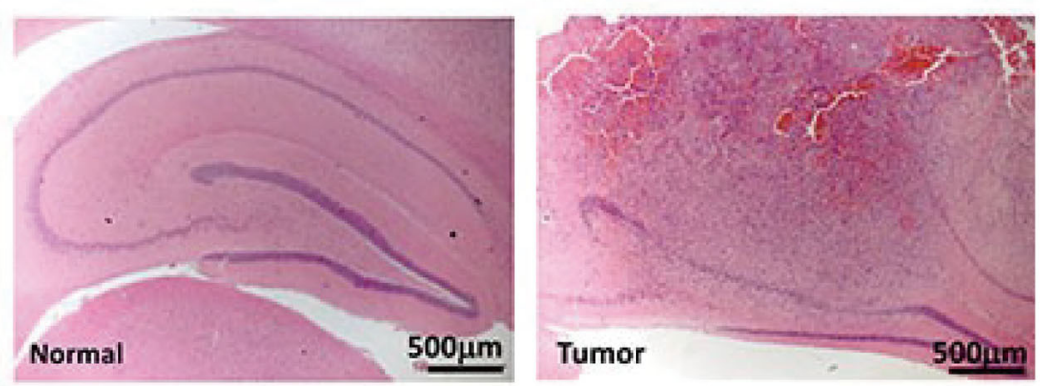

FIGURE 1 | (A) Mammary tumors were induced in tree shrew by injection of lentivirus expressing the PyMT oncogene into mammary ducts (26); (B) Hepatocellular carcinoma was induced in tree shrew by inoculated with serum from HBV-infected patient or tree shrew (27). (C) A tree shrew basal cell carcinoma model was established by infecting tail skins with lentiviral SmoA1 (28). (D) Pancreatic ductal adenocarcinoma was induced in tree shrew by Injection of lentivirus expressing KRAS-shTp53-shCdkn2a/b into the pancreatic head of the tree shrew (29). (E) Malignant glioma was induced in tree shrew by engineering a lentiviral system for the transduction of mutant H-RAS and a shRNA against tree shrew p53 (H\&E) (30).

of the human reference value. The lymphocytes, eosinophils, basophils and monocytes of tree shrews are generally within the reference range for humans (36-38). Biochemical analysis showed that only the creatinine results for tree shrews are below the lower limit of the human reference value, while the alanine aminotransferase and aspartate transaminase values are above the upper limit of the reference value. Urea, total protein, globulin, albumin, $\gamma$-glutamyl transferase, C-reactive protein and rheumatoid factor are all within the reference range for humans (36). In terms of metabolism, compared to rodents, tree shrews prefer a $5 \%$ concentration of sucrose but metabolize carbohydrates more poorly, which may account for the development of spontaneous diabetes in tree shrews (39). Moreover, the main stress-related hormone in tree shrews is cortisol, which is similar to humans, while in rats, it is corticosterone, which also suggests that tree shrews are good models for stress-related human diseases (40).

\section{TREE SHREW IMMUNE SYSTEM}

\section{Tree Shrew Humoral Immunity}

According to genomic comparisons, tree shrews are more similar to primates than to rodents in terms of immunity. The immune system of the tree shrew is conserved in many ways and can produce an immune response similar to that of humans, but in some ways, the immune response is also species-specific. Based on analysis of the structural domains and transcriptome of tree shrew immunoglobulins, tree shrews encode four classes of antibodies in addition to IgD; among these classes, IgM has the highest homology with that in primates (41). In terms of humoral immune responses, tree shrews and mice are very different. Infection with HSV-1 (Herpes simplex virus-1) produces systemic adverse reactions in mice but causes only minor infections in tree shrews (42). Similar to humans, tree shrews produce high levels of specific IgG antibodies against HSV-1, while mice produce relatively low levels of specific IgG antibodies. Similarly, the podoconjugate vaccine is successful in inducing bactericidal antibodies in tree shrews but not in mice (41). The immune behavior of tree shrews is more similar to that of humans, and tree shrews may be an important complement to mice for studying immunity.

\section{Tree Shrew Major Histocompatibility Complex (MHC)}

MHCs are important for acquired immunity in vertebrates. It is well-known that MHC class I molecules are distributed on the 
surface of almost all nucleated cells. Acquired immune responses occur through the recognition and presentation of exogenous antigenic peptides to cytotoxic Tlymphocytes $(43,44)$. The MHC class I molecule of the tree shrew consists of 357 amino acids, including a pilot peptide, $\alpha 1$ and $\alpha 2$ structural domains, an $\alpha 3$ structural domain, a transmembrane region and a cytoplasmic structural domain. Among these polymorphs, cysteine, CD8+ interaction and $\mathrm{N}$-glycosylation sites are well-conserved and similar to those of humans (45). The MHC class II region of the tree shrew contains homologs of all the human class II molecules, including the classical class II genes $H L A-D P, H L A-D Q$, and $H L A-D R$ and the non-classical class II genes HLA-DM and HLA$D O$ (15). The MHC class III gene in tree shrews is the most highly conserved compared to that in humans, differing only in the C4 region (15).

\section{Tree Shrew Pattern Recognition Receptors (PRRs)}

Upon infection with exogenous pathogenic microorganisms, PRRs can rapidly respond and lead to the production of cytokines, such as interferon (IFN), inflammatory factors and complement proteins (46). These PRRs include Tolllike receptors (TLRs), NOD-like receptors (NLRs), RIG-like receptors (RLRs), and cytoplasmic DNA receptors (47). It has been found that tree shrews have 13 TLRs (including homologs of the mammalian tTLR1-tTLR9, tTLR11-tTLR13, and tTLR10 pseudogenes). Of these, tTLR8 and tTLR9 exhibit positive selection signals, which may be associated with the adaptive immunity triggered by pathogens. The mRNA transcriptional alterations of tTLR2, tTLR3, tTLR4, and tTLR8 in tree shrews infected with hepatitis $C$ virus are consistent with the pattern observed in human hepatocytes (48). The RLRs consist of three members, namely, RIG-I, MDA5 (melanoma differentiation factor five) and LGP2 (laboratory of genetics and physiology two). RIG-I was found to be lost during the evolution of tree shrews, while MDA5 and LGP2 showed strong positive selection and induce type I IFN production. Despite the loss of RIG-I, the positively selected MDA5 locus in the tree shrew can replace RIG-I in its corresponding function (49).

\section{Tree Shrew Cytokines}

IFNs play an important role in the immune system and are essential in infectious and inflammatory diseases, autoimmune diseases and cancer, in addition to their antiviral and antibacterial effects (50). Based on the available genome-wide data of tree shrews, Li et al. (50) identified type I IFN molecules ( $\alpha$ (five subtypes), $\beta, \omega, \kappa, \varepsilon$, and $\delta$ ), type II IFN molecules $(\gamma)$, and type III IFN molecules ( $\lambda 1$ and $\lambda 2 / 3)$ by large fragment nucleic acid sequence alignment and gene prediction; of these IFN molecules, IFN $\alpha$ and IFN $\beta$ in tree shrews are very similar to those in humans. The structure of the tree shrew type III IFN- $\lambda 3$ and its receptors, IFN $\lambda$ R1 and IL10R2 (Interleukins 10 receptor 2) are also highly similar to their human counterparts (51). The structural features of type III IFN- $\lambda 3$ and its receptors, IFN $\lambda$ R 1 and IL10R2, in tree shrews are also highly similar to their human counterparts (51).
Chemokines are a family of small molecule proteins secreted by cells, and most chemokines mediate the migration of immune cells to the site of inflammatory infection, exerting antiinfective effects and modulating the immune microenvironment of tumors (52). The chemokines of the tree shrew are poorly understood, but some studies have shown that CXCL8 and its cognate receptors in tree shrews are structurally and functionally similar to and can cross react with those in primates. Human CXCL8 can bind to tree shrew CXCR1/2 to induce tree shrew PBMC migration, while overexpression of tree shrew CXCR1 in human HEK-293T cells can also promote cell migration in vitro (53). The same conclusion was also confirmed with CXCL12. Tree shrew CXCL12 and its ligand, CXCR4, are highly similar in structure to their human homologs, and the recombinant human CXCL12 protein can directly mediate the migration of tree shrew lymphocytes in vitro (54).

Interleukins (ILs) are cytokines that play an important role in inflammatory responses by activating and regulating immune cells and mediating $\mathrm{T}$ and $\mathrm{B}$ cell activation, proliferation and differentiation. Most ILs also play an essential role in tumor immunity (55-57). Immunological factors are vital indicators for the evaluation of tree shrews as models of human disease. Tree shrew interleukin 2 (tIL-2) is a 154-amino acid protein with $80 \%$ amino acid sequence homology to human IL-2. Tree shrew IL-2 has one more N-glycosylation site, and the rest of the overall structure is essentially similar to that of human IL-2 (58). Interleukin 6 (IL-6) is also important in the progression of infection, inflammation and cancer. The full length of the tree shrew IL-6 (tIL-6) gene is 5265bp, with five exons and four introns. tIL-6 has a 25 -amino acid signal peptide and a conserved structural domain, which is consistent with the protein profile of human IL-6 (59). In terms of amino acid sequence, the homology of human IL-6 with chimpanzee, monkey, tree shrew, rat and mouse IL-6 is 98.11, 96.70, 52.36, 40.65 , and $30.05 \%$, respectively (59). A phylogenetic analysis based on amino acid sequences showed that interleukin 7 (IL7) in tree shrews differs considerably from that in humans. The splice regions of the tree shrew IL7-sv2, IL7-sv4, and IL7-sv5 transcripts are similar to those of the human IL7d5, IL7d $3 / 4$, and IL7d $3 / 4 / 5$ transcripts, respectively. However, the IL7-sv1, IL7-sv3, IL7-sv6, IL7-sv7, IL7-sv8, IL7-sv9, and IL7sv10 transcripts of the tree shrew have no homology in humans (60). Interleukin 21 (IL-21), an immunomodulatory cytokine produced by natural killer (NK) cells and T cells, is pleiotropic in immune and non-immune cells and mediates the anti-tumor immune effects of $\mathrm{T}$ and $\mathrm{NK}$ cells $(61,62)$. The nucleotide sequence homology between tree shrew IL-21 (tIL-21) and human IL-21 is $83.33 \%$, and the amino acid sequence homology is $69.93 \%$. The secondary structure, hydrophobicity and surface charge distribution of tIL-21 are also similar to those of IL-21 in humans (63). In addition, tIL-21 can bind to human IL-21 antibodies, and recombinant human IL-21 can also stimulate changes in the splenic lymphocyte profile of tree shrews. In other words, tIL-21 is immune cross-reactive with human IL$21(63)$. 


\section{TREE SHREW PATHOLOGICAL PHENOTYPE OF SPONTANEOUS TUMORS}

Tree shrews can spontaneously develop tumors. Since 1966, when Elliot et al. (64) reported a case of spontaneous breast cancer in a tree shrew. Spontaneous tumors, including hepatocellular carcinoma (65), genital tumors (66), Jugulo-sternal-gland tumors (67), lung cancer (68), malignant lymphoma, skin cancer, gastrointestinal tract tumors, etc., (69) have been reported in tree shrews. It has been found that spontaneous mammary carcinomas in tree shrews have a high genetic homology with human mammary carcinomas, and some cases have familial mammary tumor characteristics. The spontaneous mammary tumors in tree shrews can be histochemically classified into tubulopapillary carcinoma and intraductal papillary adenoma. Of these tumors, $100 \%$ are positive for progesterone receptor (PR), $91.3 \%$ are positive for estrogen receptor (ER) and 4.3\% are positive for human epidermal growth factor receptor 2 (HER-2), according to immunohistochemical analysis (70). The PTEN/PIK3CA gene is frequently mutated in spontaneous mammary carcinoma in tree shrews, whereas this phenomenon has not been observed in mouse mammary carcinoma models; thus, tree shrews may be a promising animal model for this type of mammary carcinoma (71). Eight spontaneous lung tumors (four fine bronchial tubular adenomas, two fine bronchial adenocarcinomas and two squamous cell carcinomas) were observed in 54 adult tree shrews at the German Primate Center between 1978 and 1994 (68). The similarity of the histopathological phenotype of tree shrew tumors to that of human tumors provides strong evidence for the use of tree shrews as cancer models.

\section{METHODS FOR CONSTRUCTING TREE SHREW CANCER MODELS AND THEIR PATHOLOGICAL PHENOTYPES}

\section{Hepatocellular Carcinoma Model}

Hepatocellular carcinoma is one of the most prevalent cancers in the world, and it is also the second leading cause of cancerrelated death (72). To date, there has been no effective strategy for advanced hepatocellular carcinoma. Research with animal models can help increase our knowledge of hepatocellular carcinoma and improve the treatment strategies (73). As early as the 1880s Reddy et al. (20) induced hepatocellular carcinoma by feeding tree shrews highly pure aflatoxin B1 (AFB1). Six of the female tree shrews $(100 \%)$ and three of the six male tree shrews (50\%) developed hepatocellular carcinoma. The consumption of AFB1 by the tree shrews that developed hepatoma was 24$66 \mathrm{mg}$. It was later discovered that, unlike rodents, tree shrews are susceptible to hepatitis B virus (HBV) to a similar extent as humans and exhibit the same symptoms. This method induced a model of hepatocellular carcinoma in tree shrews that was more like human HBV hepatocellular carcinoma $(27,74)$. After feeding AFB1 to tree shrews infected with hepatitis B virus (200-400 $\mu \mathrm{g} / \mathrm{kg}$ body weight, once a day, six times a week), the incidence of primary hepatoma was found to be higher in the tree shrews exposed to AFB1 (52.94\%) than in those infected with $\mathrm{HBV}$ alone $(11.11 \%)$ or exposed to AFB1 alone (12.50\%) (75). Moreover, the consumption of AFB1 by the tree shrews that developed hepatoma was much lower (15$16 \mathrm{mg}$ ) than the dose used in Reddy's study. These results demonstrate a synergistic effect of HBV and AFB1 in the development of primary hepatocellular carcinoma. Later, it was also found that the hepatocellular carcinogenesis induced by AFB1 in tree shrews was significantly inhibited by oltipraz, and the gene expression profile of hepatocellular carcinoma induced by different factors was also different $(76,77)$. Differential gene expression was predominantly upregulated in the AFB1 group and downregulated in the AFB1+HBV group. This difference helps identify genes that play a key role in hepatocellular carcinogenesis. In addition, CuZn-superoxide dismutase (SOD1) and glutathione S-transferase A1 (GSTA1) were found to be downregulated in both tree shrew and human hepatocellular carcinoma tissues, and the downregulation of these proteins may have an important link to the development of hepatocellular carcinoma. As in humans, the oncogene $p 53$ was mutated in the tree shrew model of hepatocellular carcinoma. Upregulation of the p21 protein and oncogene RAS was observed in the prehepatocarcinogenesis stage, suggesting that $\mathrm{p} 21$ protein may be an early marker of hepatocellular carcinoma $(78,79)$.

\section{Mammary Cancer Model}

Mammary cancer is the most common cancer among women, and it is also the second leading cause of cancer-related death among women (80). 7, 12-dimethylbenz[a] anthracene (DMBA) is considered an effective chemical for inducing breast cancer and has been used to induce breast cancer in rodents $(81,82)$. After a study of primary mammary cancer in tree shrews, Xia et al. (71) selected female tree shrews aged 34 months in which to induce mammary cancer by the oral administration of $20 \mathrm{mg}$ DMBA every 3 weeks for a total of three times. Fifteen of these tree shrews were implanted with medroxyprogesterone acetate (MPA) pellets after 9 weeks. The results showed that the mammary cancer incidence was only $12 \%$ among the tree shrews treated with DMBA alone, while the combined use of DMBA and MPA resulted in an incidence of $50 \%$. The PTEN/PIK3C mutation was the most common mutation observed in this model. The pathological phenotypes of tree shrew mammary cancer induced by the combination of DMBA and MPA showed that these tumors were positive for $\mathrm{ER} \alpha, \mathrm{PR}$ and cytokeratin 5/6 (CK5/6) and negative for Her-2 (83). Ge et al. (26) injected a lentivirus expressing the oncogene PyMT into the mammary ducts of tree shrews to induce mammary cancer, and this approach overcame limitations of low induction efficiency and long latency period associated with the DMBA method. This method induces mammary cancer with a short latency period (about 3 weeks) and a high tumor incidence $(100 \%)$. The majority of the induced tumors are papillary carcinomas with the following characteristics: ER $(+)$, PR (+), Ki-67 (+) and Her-2 (-). Cisplatin and Epidoxorubicin significantly inhibit the progression of $P y M T$-induced mammary tumors (26). 


\section{Lung Cancer Model}

Lung cancer is the leading cause of cancer-related deaths worldwide, and in 2017, more deaths occurred from lung cancer than from breast, colorectal, prostate and brain cancers combined (1). In 1980 Rao et al. (84) studied the carcinogenic effects of 2,2'-dihydroxy-di-n-propylnitrosamine using tree shrews as experimental subjects. These tree shrews were subcutaneously injected with a dose of $250 \mathrm{mg} / \mathrm{kg}$ body weight weekly for 80 weeks. Up to 102 weeks, $78 \%$ of the female and $89 \%$ of the male tree shrews were observed to have developed pulmonary adenomas, including two males with bronchoalveolar carcinoma, and Clara cells were a major component of these tumors. Nine percent of the tree shrews also had squamous cell carcinoma of the skin and hepatocellular carcinoma. This was the first time a tree shrew lung cancer model was constructed. Bronchial epithelial hyperplasia was later induced by Chen et al. (85) using Xuanwei bituminous coal dust PM10, but the animals died within a week. Ye et al. (86) attempted to create a lung cancer model by dripping iodinated oil suspensions of 3-methylcholanthrene and diethylnitrosamine at different concentrations into the trachea of tree shrews, but unfortunately, all of the animals in the experimental group died. Although the construction of a tree shrew lung cancer model has not always been easy and has even been difficult, Che's recent successful induction of a tree shrew model of pulmonary fibrosis using bleomycin is good news (87).

\section{Basal Cell Carcinoma Model}

The skin anatomy of tree shrews is very similar to that of humans and is very suitable for use as a model of skin diseases to elucidate the underlying molecular mechanisms (35). Basal cell carcinoma (BCC) is the most commonly occurring nonmelanoma skin cancer (88). Studies have shown that the main oncogenic mutations in BCC are mutations in ptch1 and Smo, and these mutations cause abnormal activation of the Hedgehog signaling pathway $(89,90)$. Jiang et al. $(28)$ injected the lentivirus pCDH-mSmoA1 $\left(5.6 \times 10^{5} \mathrm{TU}\right)$, which expresses the SmoA1 gene, and shRNA lentivirus $\operatorname{sh} 53\left(2 \times 10^{5} \mathrm{TU}\right)$, which targets the tree shrew $p 53$ gene, into the back and tail of tree shrews. The tree shrews injected with SmoA1 alone had a BCC tumor formation rate of $40 \%$ after 2 weeks, and this rate increased to $60 \%$ after $6-8$ weeks; however, the tree shrews injected with both SmoA1 and p53-shRNA had a tumor formation rate of $70 \%$ after 2 weeks, and this rate reached $100 \%$ after 4 weeks. RT-PCR (Reverse Transcription-Polymerase Chain Reaction) showed upregulated mRNA expression of the oncogenic genes ptch1 and Gli1. The overexpression of SmoA1 successfully induced tree shrews BCC, and the downregulation of p53 accelerated the formation tree shrew BCC. The H\&E (hematoxylin-eosin staining) results show that the skin basal cell carcinoma model constructed by this method exhibits pathological features similar to those of observed in humans, such as skin cell proliferation, hair follicle rupture, hyperpigmentation and nuclear explosion expansion.

\section{Glioblastoma Model}

Glioblastoma is one of the most malignant tumors, with an average survival time of only 15 months, and no current treatment is effective in prolonging survival $(91,92)$. It is particularly vital to develop an animal model that can effectively simulate human glioblastoma to study the disease mechanisms and therapeutic strategies for treating it. In a study, the overexpression of $H-R A S$ and silencing of the $p 53$ gene were found to be effective in inducing gliomas that were identified as mesenchymal glioblastomas, the subtype with the highest degree of malignancy (30). Tumor formation began after 4 weeks after injection of $4 \mu \mathrm{l}$ of lentivirus expressing the mutant $H$-RAS gene and $s h p 53$ into the hippocampal region of the tree shrew brain. Notably, tree shrew glioblastoma has features consistent with human glioblastoma, such as necrosis, microvascular proliferation and pseudopolyps. The tree shrew glioblastoma model provides researchers with a more accurate animal model.

\section{Pancreatic Cancer Models}

Pancreatic ductal carcinoma (PDAC) accounts for $90 \%$ of human pancreatic cancers. Many studies have indicated that acinar cells are the cells of origin of PDAC (93-95). KRAS ${ }^{G 12 D}$ can induce pancreatic cancer in embryonic mice but not in adult mice (96). Tu et al. (29) found that lentiviruses can specifically infect the acinar cells of the adult tree shrew pancreas. By injecting 1 $\times 10^{7}$ lentiviral particles expressing KRAS-shTp53-shCdkn2a/b (total of $20 \mu \mathrm{l}$ ) into the pancreatic head of tree shrews in situ, a completely exposed pancreatic cancer model was induced after 3-7 weeks, whereas all the other injected control lentiviral particles failed to produce tumors. The upregulation of the oncogene KRAS and the loss of function of the tumor suppressor genes TP53, CDKN2a, and CDKN2b are thus necessary for the induction of pancreatic cancer. This tumor model involves an intermediate differentiated ductal adenocarcinoma that expresses human pancreatic cancer markers, such as keratin 19 (CK19), mucin 5 (Muc5), matrix metallopeptidase 7 (MMP7), and hes family bHLH transcription factor 1 (Hes1). The biological features of human PDAC are reproduced in this tree shrew model of pancreatic cancer, which is of great value for basic research on pancreatic cancer.

The tree shrew model of carcinoma induction in situ is more similar in all respects to the manifestations of human disease than the traditional rodent model of transplanted tumors, and thus, the tree shrew model has more research value. The methods of construction the tumor models described above, as well as their characteristics, are summarized in Table $\mathbf{1 .}$

\section{Summary and Prospects}

In summary, compared to rodents, tree shrews are more similar to humans in terms of genetics, immune system and nervous system. In addition, tree shrews have more advantages than large primates in terms of breeding, domestication, handling and ethics. As an emerging animal model of human disease, the tree shrew has unique advantages for the study of viral infections (97), depression (98) and myopia (99). The advantages of the tree shrew primary tumor model are also quite prominent in antitumour research. In addition to the physiological, biochemical and pathological similarities between tree shrews and humans, the mechanisms of the immune 
TABLE 1 | Tree shrew cancer models.

\begin{tabular}{|c|c|c|c|}
\hline Cancer models & Methods & Characteristics & References \\
\hline \multirow[t]{2}{*}{ Hepatocellular carcinoma (HCC) } & $\begin{array}{l}\text { Intermittent administration of } 2 \mathrm{mg} / \mathrm{kg} \text { of high purity } \\
\text { aflatoxin } \mathrm{B} 1 \text { in the diet For } 172 \text { weeks }\end{array}$ & $\begin{array}{l}\text { 9/12 of the tree shrews developed liver tumors between } \\
74 \text { and } 172 \text { weeks of the experiment. All nine tree } \\
\text { shrews were well to poorly differentiated hepatocellular } \\
\text { Carcinomas. }\end{array}$ & $(20)$ \\
\hline & $\begin{array}{l}\text { Tree shrews infected with human HBV are fed AFB1 } \\
\text { (200-400 } \mu \mathrm{g} / \mathrm{kg} \text { body weight per day) for a total of } \\
15-16 \mathrm{mg} 6 \text { days a week }\end{array}$ & $\begin{array}{l}\text { Within } 83-137 \text { weeks, the incidence of HCC in tree } \\
\text { shrews infected with HBV and exposed to AFB1 } \\
(52.94 \%) \text { was significantly higher than that in groups } \\
\text { infected with HBV (12.5\%) or only exposed to AFB1 } \\
(11.11 \%) \text {. Thirteen cases of liver tumors were all } \\
\text { hepatocellular carcinoma, including eight cases of } \\
\text { trabecular type, three of adenoid type, and two of } \\
\text { poorly-differentiated type. The tumors were single or } \\
\text { multi-nodular. }\end{array}$ & $(75)$ \\
\hline \multirow[t]{2}{*}{ Mammary cancer } & $\begin{array}{l}30 \text { tree shrews were administered intragastrically with } \\
1 \mathrm{ml} \text { peanut oil containing } 20 \mathrm{mg} \text { DMBA, once every } 3 \\
\text { weeks for a total of } 3 \text { times. After } 9 \text { weeks, } 15 \text { of them } \\
\text { were implanted with } 150 \mathrm{mg} \text { MPA. }\end{array}$ & $\begin{array}{l}\text { The combined administration of DMBA + MPA has a } \\
\text { tumor formation rate of 50\%, Immunohistochemistry: ER } \\
(+), \text { PR (+), CK5/6 (+), Her- } 2(-) \text {. PTEN and PIK3C } \\
\text { genes are frequently mutated in this breast cancer model }\end{array}$ & $(71)$ \\
\hline & $\begin{array}{l}10 \text { ul of lentivirus overexpressing the PyMT cancer gene } \\
\text { was injected into the mammary ducts of the tree shrews. }\end{array}$ & $\begin{array}{l}\text { The incubation period was } 3 \text { weeks, after } 7 \text { weeks all } \\
\text { tree shrews developed mammary tumors, mainly } \\
\text { papillary carcinomas. Immunohistochemistry: ER (+), PR } \\
(+), \text { Her-2 (-). }\end{array}$ & $(26)$ \\
\hline Lung cancer & $\begin{array}{l}\text { DHPH was injected subcutaneously once a week at } 250 \\
\text { mg/kg body weight for } 80 \text { weeks. }\end{array}$ & $\begin{array}{l}\text { Up to } 102 \text { weeks } 78 \% \text { of female and } 89 \% \text { of male tree } \\
\text { shrews were observed to have developed lung } \\
\text { adenomas, with Clara cells being a major component of } \\
\text { these tumors, and two of these were bronchoalveolar } \\
\text { carcinomas. A further } 9 \% \text { of the tree shrews had } \\
\text { squamous cell carcinoma of the skin and hepatocellular } \\
\text { carcinoma. }\end{array}$ & (84) \\
\hline Basal cell carcinoma & $\begin{array}{l}\text { The lentivirus expressing the oncogene SmoA1 ( } 5.6 \times \\
\left.10^{5} \mathrm{TU}\right) \text { and the shp53 }\left(2 \times 10^{5} \mathrm{TU}\right) \text { lentivirus were } \\
\text { injected into the skin of the back and tail of the tree } \\
\text { shrew, with a total volume of } 10 \mu \mathrm{l} \text {. }\end{array}$ & $\begin{array}{l}\text { The combined injection of SmoA1 and p53-shRNA virus } \\
\text { group showed a BCC-like phenotype of } 70 \% \text { after } 2 \\
\text { weeks, and the tumor formation rate reached } 100 \% \text { after } \\
4 \text { weeks. Ptch1 and Gli1 mRNA expressions were } \\
\text { up-regulated. }\end{array}$ & $(28)$ \\
\hline Glioblastoma (GBM) & $\begin{array}{l}4 \mu \text { l lentiviruses }\left(3 \times 10^{11} / \mathrm{ml} \text { titered by real-time PCR) }\right. \\
\text { expressing } \mathrm{H} \text {-RAS and shp53 were injected into the } \\
\text { hippocampus of the tree shrew. }\end{array}$ & $\begin{array}{l}D H 1, T E R T, E G F R, P T E N, \text { ATRX and other key factors } \\
\text { are expressed in gliomas as in human GBM, and EGFR } \\
\text { is upregulated in tree shrew GBM. }\end{array}$ & $(30)$ \\
\hline Pancreatic cancer & $\begin{array}{l}\text { Injection of } 20 \text { ul lentivirus expressing } \\
\text { KRAS-shTp53-shCdkn2a/b into the pancreatic head of } \\
\text { the tree shrew }\end{array}$ & $\begin{array}{l}\text { The tumor formed after } 3-7 \text { weeks, which was a } \\
\text { moderately differentiated ductal adenocarcinoma. } \\
\text { Immunohistochemistry: CK19 (+), Muc (+), MMP7 (+), } \\
\text { Hes1 (+). }\end{array}$ & (29) \\
\hline
\end{tabular}

TU: transducing units; (+): positive; (-): negative.

response in tree shrews are also highly conserved with those in humans (53). Analysis of drug targets and predictions at the genomic and transcriptional level in tree shrews revealed 3,482 proteins predicted as drug targets, including homologs for cancer chemotherapy, depression, and cardiovascular disease. More than half of these target proteins have higher similarity to human target proteins than those in mice (100). In other words, the tree shrew model is of greater clinical value in terms of research about tumor therapies, particularly immunotherapies. However, there are still relatively few types of tree shrew tumor models because little research has been done on tree shrews. A welldeveloped method for constructing tree shrew tumor models is one of the keys to the extension of tree shrew applications. Methods for constructing tree shrew tumor models are still being explored, and the existing methods still have some drawbacks, such as long construction time, difficult operation, low success rate and difficulty in standardization. Mechanistic studies at the cellular and small molecule levels in tree shrews are of great importance for improving the modeling schemes. Based on the current study, the approach of using lentivirus transduction into cells in situ to overexpress oncogenes or inhibit tumor suppressor gene expression seems to be more effective for the construction of tree shrew tumor models, while the approach of drug induction appears to require longer durations and have a lower success rate.

Fortunately, the Kunming Institute of Zoology has achieved standardized captive domestication of tree shrews and can provide more than 1,000 experimental tree shrews each year 
(11). However, there are currently some problems with the use of tree shrews as tumor models. The greatest problem is that there are currently no inbred tree shrew strains with clear genetic backgrounds. The large individual differences between tree shrews are one of the factors that make it difficult to standardize experiments. Fortunately, scientists at CAS have now started to work on establishing tree shrew strains. There is still a long way to go in generating inbred strains of tree shrews, but this is a crucial key step for standardizing experimental tree shrews. In addition, supporting tools for tree shrews research have not yet been developed. For example, tree shrew cell lines, tree shrew-specific antibodies, corresponding assays, etc., must be developed. However, the homology between tree shrews and humans makes some of the immunizations cross-reactive, and thus, in many cases, human cell lines and antibodies can be used. There is no doubt that the tree shrew is becoming increasingly important in the field of medical research, and the results achieved are considerable. Further study of the tree shrew's immune system and its physiological and biochemical characteristics may provide more insight into the development

\section{REFERENCES}

1. Siegel RL, Miller KD, Jemal A. Cancer statistics, 2020. CA Cancer J Clin. (2020) 70:7-30. doi: $10.3322 /$ caac. 21590

2. Mestas J, Hughes CC. Of mice and not men: differences between mouse and human immunology. J Immunol. (2004) 172:2731-8. doi: 10.4049/jimmunol.172.5.2731

3. Pandey UB, Nichols CD. Human disease models in Drosophila melanogaster and the role of the fly in therapeutic drug discovery. Pharmacol Rev. (2011) 63:411-36. doi: 10.1124/pr.110.003293

4. Azushima K, Gurley SB, Coffman TM. Modelling diabetic nephropathy in mice. Nat Rev Nephrol. (2018) 14:48-56. doi: 10.1038/nrneph.20 17.142

5. Esteves PJ, Abrantes J, Baldauf HM, BenMohamed L, Chen Y, Christensen N, et al. The wide utility of rabbits as models of human diseases. Exp Mol Med. (2018) 50:1-10. doi: 10.1038/s12276-018-0094-1

6. Pinho SS, Carvalho S, Cabral J, Reis CA, Gartner F. Canine tumors: a spontaneous animal model of human carcinogenesis. Transl Res. (2012) 159:165-72. doi: 10.1016/j.trsl.2011.11.005

7. Iqbal MA, Hong K, Kim JH, Choi Y. Severe combined immunodeficiency pig as an emerging animal model for human diseases and regenerative medicines. BMB Rep. (2019) 52:625-34. doi: 10.5483/BMBRep.2019.52.11.267

8. Weinberger MH. Hypertensive rat model. J Am Soc Hypertens. (2013) 7:1-2. doi: 10.1016/j.jash.2012.12.005

9. De Wit E, Feldmann F, Cronin J, Jordan R, Okumura A, Thomas T, et al. Prophylactic and therapeutic remdesivir (GS-5734) treatment in the rhesus macaque model of MERS-CoV infection. Proc Natl Acad Sci USA. (2020) 117:6771-6. doi: 10.1073/pnas.1922083117

10. Xiao J, Liu R, Chen CS. Tree shrew (Tupaia belangeri) as a novel laboratory disease animal model. Zool Res. (2017) 38:127-37. doi: 10.24272/j.issn.2095-8137.2017.033

11. Xu L, Zhang Y, Liang B, Lu LB, Chen CS, Chen YB, et al. Tree shrews under the spot light: emerging model of human diseases. Zool Res. (2013) 34:59-69. doi: 10.3724/SP.J.1141.2013.02059

12. $\mathrm{Xu} \mathrm{L}$, Fan $\mathrm{Y}$, Jiang $\mathrm{XL}$, Yao YG. Molecular evidence on the phylogenetic position of tree shrews. Zool Res. (2013) 34:70-6. doi: 10.3724/SP.J.1141.2013.02070

13. Tsukiyama-Kohara K, Kohara M. Tupaia belangeri as an experimental animal model for viral infection. Exp Anim. (2014) 63:367-74. doi: 10.1538/expanim. 63.367 of tumor models. It is believed that in the near future, tree shrews could replace large primates as the most powerful tool for cancer-related pre-clinical research.

\section{AUTHOR CONTRIBUTIONS}

$\mathrm{YH}$ and $\mathrm{ZD}$ contributed to the conception and design of the review. TL and HP wrote the manuscript. LZ, PW, and JH revised the manuscript. All authors contributed to manuscript revision, read, and approved the submitted version.

\section{FUNDING}

This work was supported by the National Natural Science Foundation of China (No. 82072340), the Major national science and technology projects-Major new drug creation (2019ZX09301-132); Changjiang Scholars and Innovative Research Team in University (No. IRT_15R13); Guangxi Science and Technology Base and Talent Special Project (No. AD17129003).

14. Yao YG. Creating animal models, why not use the Chinese tree shrew (Tupaia belangeri chinensis)? Zool Res. (2017) 38:118-26. doi: 10.24272/j.issn.2095-8137.2017.032

15. Fan Y, Huang ZY, Cao CC, Chen CS, Chen YX, Fan DD, et al. Genome of the Chinese tree shrew. Nat Commun. (2013) 4:1426. doi: 10.1038/ncomms2416

16. Fan Y, Ye MS, Zhang JY, Xu L, Yu DD, Gu TL, et al. Chromosomal level assembly and population sequencing of the Chinese tree shrew genome. Zool Res. (2019) 40:506-21. doi: 10.24272/j.issn.2095-8137.2019.063

17. Sanada T, Tsukiyama-Kohara K, Shin IT, Yamamoto N, Kayesh MEH, Yamane D, et al. Construction of complete Tupaia belangeri transcriptome database by whole-genome and comprehensive RNA sequencing. Sci Rep. (2019) 9:12372. doi: 10.1038/s41598-019-48867-x

18. Fan Y, Yu D, Yao YG. Tree shrew database (TreeshrewDB): a genomic knowledge base for the Chinese tree shrew. Sci Rep. (2014) 4:7145. doi: $10.1038 /$ srep07145

19. Zhao Y, Wang J, Kuang D, Xu J, Yang M, Ma C, et al. Susceptibility of tree shrew to SARS-CoV-2 infection. Sci Rep. (2020) 10:16007. doi: 10.1038/s41598-020-72563-w

20. Reddy JK, Svoboda DJ, Rao MS. Induction of liver tumors by aflatoxin B1 in the tree shrew (Tupaia glis), a nonhuman primate. Cancer Res. (1976) 36:151-60.

21. Shi Z, Xing H, Qi C, Fang M, Fu J, Zhang X. Chinese tree shrews as a primate experimental animal eligible for the study of alcoholic liver disease: characterization and confirmation by MRItree. Exp Anim. (2020) 69:110-8. doi: 10.1538/expanim.19-0073

22. Steckler T, Prickaerts J. Depressed neurogenesis and its role in the genesis of depression. Commentary on Fuchs et al., examining novel concepts of the pathophysiology of depression in the chronic psychosocial stress paradigm in tree shrews. Behav Pharmacol. (2004) 15:365-8. doi: 10.1097/00008877-200409000-00008

23. Wang YY, Wang JD, Wang L, Dan QQ, Xia QJ, Wang TH, et al. Establishment of neurobehavioral assessment system in tree shrew SCT model. J Mol Neurosci. (2020) 70:308-19. doi: 10.1007/s12031-019-01414-9

24. Liu XH, Yao YG. Characterization of 12 polymorphic microsatellite markers in the Chinese tree shrew (Tupaia belangeri chinensis). Zool Res. (2013) 34:E62-8. doi: 10.3724/SP.J.1141.2013.E02E62

25. Li CH, Yan LZ, Ban WZ, Tu Q, Wu Y, Wang L, et al. Long-term propagation of tree shrew spermatogonial stem cells in culture and successful generation of transgenic offspring. Cell Res. (2017) 27:241-52. doi: 10.1038/cr.2016.156

26. Ge GZ, Xia HJ, He BL, Zhang HL, Liu WJ, Shao M, et al. Generation and characterization of a breast carcinoma model by PyMT overexpression 
in mammary epithelial cells of tree shrew, an animal close to primates in evolution. Int J Cancer. (2016) 138:642-51. doi: 10.1002/ijc.29814

27. Yang C, Ruan P, Ou C, Su J, Cao J, Luo C, et al. Chronic hepatitis B virus infection and occurrence of hepatocellular carcinoma in tree shrews (Tupaia belangeri chinensis). Virol J. (2015) 12:26. doi: 10.1186/s12985-015-0256-x

28. Jiang LP, Shen QS, Yang CP, Chen YB. Establishment of basal cell carcinoma animal model in Chinese tree shrew (Tupaia belangeri chinensis). Zool Res. (2017) 38:180-90.

29. Tu Q, Yang D, Zhang X, Jia X, An S, Yan L, et al. A novel pancreatic cancer model originated from transformation of acinar cells in adult tree shrew, a primate-like animal. Dis Model Mech. (2019) 12:dmm038703. doi: $10.1242 / \mathrm{dmm} .038703$

30. Tong Y, Hao J, Tu Q, Yu H, Yan L, Li Y, et al. A tree shrew glioblastoma model recapitulates features of human glioblastoma. Oncotarget. (2017) 8:17897-907. doi: 10.18632/oncotarget.15225

31. Romer S, Bender H, Knabe W, Zimmermann E, Rubsamen R, Seeger J, et al. Neural progenitors in the developing neocortex of the northern tree shrew (Tupaia belangeri) show a closer relationship to gyrencephalic primates than to lissencephalic rodents. Front Neuroanat. (2018) 12:29. doi: 10.3389/fnana.2018.00029

32. Lihong X, Heng L, Gyanwali B, Meichan Z, Kaiquan Z, Kai S, et al. Micro-computed tomography and microdissection of the temporal bone of tree shrews. Ann Anat. (2016) 208:69-77. doi: 10.1016/j.aanat.2015. 08.005

33. Li R, Zanin M, Xia X, Yang Z. The tree shrew as a model for infectious diseases research. J Thorac Dis. (2018) 10:S2272-S2279. doi: $10.21037 /$ jtd.2017.12.121

34. Kakuni M, Makita T, Wijayanto H, Hondo E, Kiso Y. Histological study on intestinal diverticulum of tree shrew (Tupaia javanica). Exp Anim. (2002) 51:411-5. doi: 10.1538/expanim.51.411

35. Zhang J, Luo RC, Man XY, Lv LB, Yao YG, Zheng M. The anatomy of the skin of the Chinese tree shrew is very similar to that of human skin. Zool Res. (2020) 41:208-12. doi: 10.24272/j.issn.2095-8137.2020.028

36. Xie L, Qin X, Chen XY, Li S, Huang CN, Deng JH. Normal physiological laboratory value of tree shrew bred in laboratory. Sichuan $J$ Zool. (2007) 03:682-5.

37. Ma XT, Li FL, Jiang HJ, Li WH, Zhang Y, Du TY. Detection and comparison of physiological indexes in the wild and laboratory tree shrew. Zool Res. (2011) 32:4-10. doi: 10.3724/SP.J.1141.2011.01004

38. Feng Y, Xia W, Ji K, Lai Y, Feng Q, Chen H, et al. Hemogram study of an artificially feeding tree shrew (Tupaia belangeri chinensis). Exp Anim. (2020) 69:80-91. doi: 10.1538/expanim.19-0079

39. Liang $B, W u$ XY. Progress on nonhuman primate models of diabetes mellitus. Zool Res. (2011) 32:91-6. doi: 10.3724/SP.J.1141.2011.01091

40. Wang J, Xu XL, Ding ZY, Mao RR, Zhou QX, Lu LB, et al. Basal physiological parameters in domesticated tree shrews (Tupaia belangeri chinensis). Zool Res. (2013) 34:E69-74. doi: 10.3724/SP.J.1141.2013. E02E69

41. Zhang J, Xiao H, Bi Y, Long Q, Gong Y, Dai J, et al. Characteristics of the tree shrew humoral immune system. Mol Immunol. (2020) 127:175-85. doi: 10.1016/j.molimm.2020.09.009

42. Li L, Li Z, Wang E, Yang R, Xiao Y, Han H, et al. Herpes simplex virus 1 infection of tree shrews differs from that of mice in the severity of acute infection and viral transcription in the peripheral nervous system. $J$ Virol. (2016) 90:790-804. doi: 10.1128/JVI.02258-15

43. Carrington M, O'Brien SJ. The influence of HLA genotype on AIDS. Annu Rev Med. (2003) 54:535-51. doi: 10.1146/annurev.med.54.101601. 152346

44. Cruz FM, Colbert JD, Merino E, Kriegsman BA, Rock KL. The biology and underlying mechanisms of cross-presentation of exogenous antigens on MHC-I molecules. Annu Rev Immunol. (2017) 35:149-76. doi: 10.1146/annurev-immunol-041015-055254

45. Zhang XH, Dai ZX, Zhang GH, Han JB, Zheng YT. Molecular characterization, balancing selection, and genomic organization of the tree shrew (Tupaia belangeri) MHC class I gene. Gene. (2013) 522:147-55. doi: 10.1016/j.gene.2013.03.113

46. Takeuchi O, Akira S. Pattern recognition receptors and inflammation. Cell. (2010) 140:805-20. doi: 10.1016/j.cell.2010.01.022
47. Barbalat R, Ewald SE, Mouchess ML, Barton GM. Nucleic acid recognition by the innate immune system. Annu Rev Immunol. (2011) 29:185-214. doi: 10.1146/annurev-immunol-031210-101340

48. Yu D, Wu Y, Xu L, Fan Y, Peng L, Xu M, et al. Identification and characterization of toll-like receptors (TLRs) in the Chinese tree shrew (Tupaia belangeri chinensis). Dev Comp Immunol. (2016) 60:127-38. doi: 10.1016/j.dci.2016.02.025

49. Xu L, Yu D, Fan Y, Peng L, Wu Y, Yao YG. Loss of RIG-I leads to a functional replacement with MDA5 in the Chinese tree shrew. Proc Natl Acad Sci USA. (2016) 113:10950-5. doi: 10.1073/pnas.1604939113

50. Li ML, Tian WW, Gao YD, Guo Y, Huang JF, Zhang HT. Genomewide prediction of interferon family members of tree shrew and their molecular characteristics analysis. Zool Res. (2012) 33:67-74. doi: 10.3724/SP.J.1141.2012.01067

51. Li ML, Xu WW, Gao YD, Guo Y, Wang WJ, Wang C, et al. Interferon-lambda3 (IFN-lambda3) and its cognate receptor subunits in tree shrews (Tupaia belangeri): genomic sequence retrieval, molecular identification and expression analysis. PLOS ONE. (2013) 8:e60048. doi: 10.1371/journal.pone. 0060048

52. Vilgelm AE, Richmond A. Chemokines modulate immune surveillance in tumorigenesis, metastasis, and response to immunotherapy. Front Immunol. (2019) 10:333. doi: 10.3389/fimmu.2019.00333

53. Jiang Z, Gao B, Hu M, Ding L, Lan Z, Yu M, et al. Conserved structure and function of chemokine CXCL8 between Chinese tree shrews and humans. Gene. (2018) 677:149-62. doi: 10.1016/j.gene.2018.07.025

54. Chen G, Wang W, Meng S, Zhang L, Wang W, Jiang Z, et al. CXC chemokine CXCL12 and its receptor CXCR4 in tree shrews (Tupaia belangeri): structure, expression and function. PLoS ONE. (2014) 9:e98231. doi: 10.1371/journal.pone.0098231

55. Sivakumar PV, Foster DC, Clegg CH. Interleukin-21 is a T-helper cytokine that regulates humoral immunity and cell-mediated anti-tumour responses. Immunology. (2004) 112:177-82. doi: 10.1111/j.1365-2567.2004.01886.x

56. Dmitrieva OS, Shilovskiy IP, Khaitov MR, Grivennikov SI. Interleukins 1 and 6 as main mediators of inflammation and cancer. Biochemistry (Mosc). (2016) 81:80-90. doi: 10.1134/S0006297916020024

57. Kumari N, Dwarakanath BS, Das A, Bhatt AN. Role of interleukin-6 in cancer progression and therapeutic resistance. Tumour Biol. (2016) 37:11553-72. doi: 10.1007/s13277-016-5098-7

58. Huang XY, Li ML, Xu J, Gao YD, Wang WG, Yin AG, et al. Analysis of the molecular characteristics and cloning of full-length coding sequence of interleukin-2 in tree shrews. Zool Res. (2013) 34:121-6. doi: 10.3724/SP.J.1141.2013.02121

59. Han Y, Sun X, Kuang D, Tong P, Lu C, Wang W, et al. Characterization of tree shrew (Tupaia belangeri) interleukin-6 and its expression pattern in response to exogenous challenge. Int J Mol Med. (2017) 40:1679-90. doi: $10.3892 /$ ijmm.2017.3168

60. Yu D, Xu L, Liu XH, Fan Y, Lu LB, Yao YG. Diverse interleukin-7 mRNA transcripts in Chinese tree shrew (Tupaia belangeri chinensis). PLoS ONE. (2014) 9:e99859. doi: 10.1371/journal.pone.0099859

61. Leonard WJ, Wan CK. IL-21 signaling in immunity. F1000Res. (2016) 5:F1000. doi: 10.12688/f1000research.7634.1

62. Chabab G, Bonnefoy N, Lafont V. IL-21 signaling in the tumor microenvironment. Adv Exp Med Biol. (2020) 1240:73-82. doi: 10.1007/978-3-030-38315-2_6

63. Ding R, Zhang H, Zhang L, Zhao W, Li Y, Yang J, et al. Assessment of sequence homology and immunologic cross-reactivity between tree shrew (Tupaia belangeri) and human IL-21. PLoS ONE. (2017) 12:e0176707. doi: 10.1371/journal.pone. 0176707

64. Elliot OS, Elliot MW, Lisco H. Breast cancer in a tree shrew (Tupaia glis). Nature. (1966) 211:1105. doi: 10.1038/2111105a0

65. Hofmann W, Moller P, Schwaier A, Flugel RM, Zoller L, Darai G. Malignant tumours in Tupaia (tree shrew). J Med Primatol. (1981) 10:15563. doi: $10.1159 / 000460067$

66. Brack M. Malignant Leydig cell tumour in a Tupaia belangeri: case report and literature review of male genital tumours in non-human primates. Lab Anim. (1988) 22:131-4. doi: 10.1258/002367788780864484

67. Brack M. Jugulo-sternal-gland tumors in male tree shrews (Tupaia belangeri). Lab Anim Sci. (1991) 41:536-9. 
68. Brack M, Schwartz P, Heinrichs T, Schultz M, Fuchs E. Tumors of the respiratory tract observed at the German Primate Center, 1978-1994. J Med Primatol. (1996) 25:424-34. doi: 10.1111/j.1600-0684.1996.tb00039.x

69. Brack M. Spontaneous tumours in tree shrews (Tupaia belangeri): population studies. J Comp Pathol. (1998) 118:301-16. doi: 10.1016/S0021-9975(07)80006-5

70. Hai-Ying C, Tanaka Y, Hifumi T, Shoji K, Kayesh MEH, Hashem MA, et al. Pathological and genetic aspects of spontaneous mammary gland tumor in Tupaia belangeri (tree shrew). PLOS ONE. (2020) 15:e0233232. doi: 10.1371/journal.pone.0233232

71. Xia HJ, He BL, Wang CY, Zhang HL, Ge GZ, Zhang YX, et al. PTEN/PIK3CA genes are frequently mutated in spontaneous and medroxyprogesterone acetate-accelerated 7,12-dimethylbenz(a)anthraceneinduced mammary tumours of tree shrews. Eur J Cancer. (2014) 50:3230-42. doi: 10.1016/j.ejca.2014.10.012

72. Bray F, Ferlay J, Soerjomataram I, Siegel RL, Torre LA, Jemal A. Global cancer statistics 2018: GLOBOCAN estimates of incidence and mortality worldwide for 36 cancers in 185 countries. CA Cancer J Clin. (2018) 68:394-424. doi: $10.3322 /$ caac. 21492

73. Serra, M., Columbano, A, Perra, A, Kowalik MA. Animal Models: A Useful Tool to Unveil Metabolic Changes in Hepatocellular Carcinoma. Cancers (Basel). (2020) 12:3318. doi: 10.3390/cancers 12113318

74. Su JJ. Experimental infection of human hepatitis B virus (HBV) in adult tree shrews. Zhonghua Bing Li Xue Za Zhi. (1987) 16:103-6.

75. Yan RQ, Su JJ, Huang DR, Gan YC, Yang C, Huang GH. Human hepatitis B virus and hepatocellular carcinoma. II. Experimental induction of hepatocellular carcinoma in tree shrews exposed to hepatitis B virus and aflatoxin B1. J Cancer Res Clin Oncol. (1996) 122:289-95. doi: 10.1007/BF01261405

76. Li Y, Su JJ, Qin LL, Yang C, Luo D, Ban KC, et al. Chemopreventive effect of oltipraz on AFB(1)-induced hepatocarcinogenesis in tree shrew model. World J Gastroenterol. (2000) 6:647-50. doi: 10.3748/wjg.v6.i5.647

77. Li Y, Su JJ, Cao J, Ou C, Qiu XK, Yang C, et al. Differentially expressed genes in hepatocellular carcinoma of tree shrew induced by different factors. Chin J Cancer. (2003) 22:1018-22.

78. Su JJ, Li Y, Ban KC, Qin LL, Wang HY, Yang C, et al. Alteration of the p53 gene during tree shrews' hepatocarcinogenesis. Hepatobiliary Pancreat Dis Int. (2003) 2:612-6.

79. Su JJ, Ban KC, Li Y, Qin LL, Wang HY, Yang C, et al. Alteration of p53 and p 21 during hepatocarcinogenesis in tree shrews. World J Gastroenterol. (2004) 10:3559-63. doi: 10.3748/wjg.v10.i24.3559

80. Tabor S, Szostakowska-Rodzos M, Fabisiewicz A, Grzybowska EA. How to predict metastasis in luminal breast cancer? Current solutions and future prospects. Int J Mol Sci. (2020) 21:8415. doi: 10.3390/ijms21218415

81. Wurz GT, Marchisano-Karpman C, DeGregorio MW. Ineffectiveness of American ginseng in the prevention of dimethylbenzanthraceneinduced mammary tumors in mice. Oncol Res. (2006) 16:251-60. doi: 10.3727/000000006783981017

82. Akhouri V, Kumari M, Kumar A. Therapeutic effect of Aegle marmelos fruit extract against DMBA induced breast cancer in rats. Sci Rep. (2020) 10:18016. doi: 10.1038/s41598-020-72935-2

83. Chen M, Ou C, Yang C, Yang W, Qin Q, Jiang W, et al. A Novel Animal Model of Induced Breast Precancerous Lesion in Tree Shrew. Biol Pharm Bull. (2019) 42:580-5. doi: 10.1248/bpb.b18-00688

84. Rao MS, Reddy JK. Carcinogenicity of 2,2'-dihydroxy-di-npropylnitrosamine in the tree shrew (Tupaia glis): light and electron microscopic features of pulmonary adenomas. J Natl Cancer Inst. (1980) 65:835-40. doi: 10.1093/jnci/65.4.835

85. Chen X, He M, Li G, Zhou Y, Zhao G, Lei Y, et al. Study of the changes on tree shrew bronchial epithelium induced by xuanwei bituminous coal dust. Chin J Lung Cancer. (2015) 18:469-74. doi: 10.3779/j.issn.1009-3419. 2015.08 .01
86. Ye L, He M, Huang Y, Zhao G, Lei Y, Zhou Y, et al. Tree shrew as a new animal model for the study of lung cancer. Oncol Lett. (2016) 11:2091-5. doi: 10.3892/ol.2016.4156

87. Che P, Wang M, Larson-Casey JL, Hu RH, Cheng Y, El Hamdaoui M, et al. A novel tree shrew model of pulmonary fibrosis. Lab Invest. (2020) 101:116-24. doi: 10.1038/s41374-020-00476-3

88. Rubin AI, Chen EH, Ratner D. Basal-cell carcinoma. N Engl J Med. (2005) 353:2262-9. doi: 10.1056/NEJMra044151

89. Bonilla X, Parmentier L, King B, Bezrukov F, Kaya G, Zoete V, et al. Genomic analysis identifies new drivers and progression pathways in skin basal cell carcinoma. Nat Genet. (2016) 48:398-406. doi: 10.1038/ng.3525

90. Sekulic A, Von Hoff D. Hedgehog pathway inhibition. Cell. (2016) 164:831. doi: 10.1016/j.cell.2016.02.021

91. Stupp R, Hegi ME, Mason WP, van den Bent MJ, Taphoorn MJ, Janzer RC, et al. Effects of radiotherapy with concomitant and adjuvant temozolomide versus radiotherapy alone on survival in glioblastoma in a randomised phase III study: 5-year analysis of the EORTC-NCIC trial. Lancet Oncol. (2009) 10:459-66. doi: 10.1016/S1470-2045(09)70025-7

92. Ohka F, Natsume A, Wakabayashi T. Current trends in targeted therapies for glioblastoma multiforme. Neurol Res Int. (2012) 2012:878425. doi: $10.1155 / 2012 / 878425$

93. Kozuka S, Sassa R, Taki T, Masamoto K, Nagasawa S, Saga S, et al. Relation of pancreatic duct hyperplasia to carcinoma. Cancer. (1979) 43:141828. doi: 10.1002/1097-0142(197904)43:4<1418::AID-CNCR2820430431>3 $0 . \mathrm{CO} ; 2-\mathrm{O}$

94. Kopp JL, von Figura G, Mayes E, Liu FF, Dubois CL, Morris JP, et al. Identification of Sox9-dependent acinar-to-ductal reprogramming as the principal mechanism for initiation of pancreatic ductal adenocarcinoma. Cancer Cell. (2012) 22:737-50. doi: 10.1016/j.ccr.2012.10.025

95. Maresch R, Mueller S, Veltkamp C, Ollinger R, Friedrich M, Heid I, et al. Multiplexed pancreatic genome engineering and cancer induction by transfection-based CRISPR/Cas9 delivery in mice. Nat Commun. (2016) 7:10770 doi: $10.1038 /$ ncomms 10770

96. Guerra C, Collado M, Navas C, Schuhmacher AJ, Hernandez-Porras I, Canamero $\mathrm{M}$, et al. Pancreatitis-induced inflammation contributes to pancreatic cancer by inhibiting oncogene-induced senescence. Cancer Cell. (2011) 19:728-39. doi: 10.1016/j.ccr.2011.05.011

97. Wang E, Ye Y, Zhang K, Yang J, Gong D, Zhang J, et al. Longitudinal transcriptomic characterization of viral genes in HSV-1 infected tree shrew trigeminal ganglia. Virol J. (2020) 17:95. doi: 10.1186/s12985-020-01344-8

98. Meng X, Shen F, Li C, Li Y, Wang X. Depression-like behaviors in tree shrews and comparison of the effects of treatment with fluoxetine and carbetocin. Pharmacol Biochem Behav. (2016) 145:1-8. doi: 10.1016/j.pbb.2016.03.006

99. Sajdak BS, Salmon AE, Cava JA, Allen KP, Freling S, Ramamirtham R, et al. Noninvasive imaging of the tree shrew eye: wavefront analysis and retinal imaging with correlative histology. Exp Eye Res. (2019) 185:107683. doi: 10.1016/j.exer.2019.05.023

100. Zhao F, Guo X, Wang Y, Liu J, Lee WH, Zhang Y. Drug target mining and analysis of the Chinese tree shrew for pharmacological testing. PLoS ONE. (2014) 9:e104191. doi: 10.1371/journal.pone.0104191

Conflict of Interest: The authors declare that the research was conducted in the absence of any commercial or financial relationships that could be construed as a potential conflict of interest.

Copyright (c) $2021 \mathrm{Lu}$, Peng, Zhong, Wu, He, Deng and Huang. This is an open-access article distributed under the terms of the Creative Commons Attribution License (CC $B Y)$. The use, distribution or reproduction in other forums is permitted, provided the original author(s) and the copyright owner(s) are credited and that the original publication in this journal is cited, in accordance with accepted academic practice. No use, distribution or reproduction is permitted which does not comply with these terms. 